\title{
DIY Ecology Class: Transitioning field activities to an online format
}

\author{
Catherine Creech $^{1}$ and Walter Shriner ${ }^{1}$ \\ ${ }^{1}$ Mt. Hood Community College
}

June 10, 2020

\begin{abstract}
The COVID-19 pandemic has forced the transition of many traditional face-to-face classes into an online format with little time to prepare best practice guidelines. In this article we share ways to adapt a group field activity into an individual lab assignment that can be completed during shelter-in-place restrictions. We address the tactics, difficulties, successes, and ideas for future applications while staying mindful of the ways in which this pandemic has highlighted the inequities of the classroom.
\end{abstract}

\section{Key words}

Online teaching, remote instruction, ecology, COVID-19, biodiversity sampling, quadrat

\section{Background}

Teaching ecology : Ecology class is a faculty favorite for several reasons. For those of us with backgrounds in conservation biology, biodiversity, and evolution, teaching ecology is like spending time with a dear friend. We get to revisit the ideas and concepts that made us passionate about biology in the first place and our excitement is vivid, tangible, and uncontainable. Our love for the subject bubbles over when we lecture, when we explain a lab procedure, or when we get behind the wheel of our 15-passenger vans full of eager students. Ecology class requires us to take ourselves a little less seriously. We kneel in the dirt, sweat while climbing the trail, and get mud under our fingernails while showing our students the interconnected beauty of the world. Ecology class is a great equalizer. Each person in the room, student and faculty alike, breathe the same air and are exposed to the same environmental factors, reminding us that we're all in this together. Our differences are less notable when we're crouching by the same stream or posing for a selfie together in front of a waterfall. Ecology class welcomes innovation and ambiguity. Students create novel experiments knowing that they are in control of the research and interpretation. Fundamentally, ecology class highlights two major principles in the sciences: change is the only constant; and no organism exists in isolation.

Challenges to moving online: Moving our ecology materials online left us with a sense of loss. We mourn the cancelled fieldwork, class trips, and group hikes. We lament the loss of hands-on learning that ecology class encourages, the walks around campus, the exploration of what is hidden in plain sight. Specifically, we rue the way remote learning highlights the inequity in our classrooms. Students who lack computers are relegated to working from smart phones or ancient tablets. Those who lack Internet spend hours sitting in front of McDonalds in order to use the free WIFI the filters into the parking lot. Many of our students are parents, now suddenly teachers themselves trying to figure out how to navigate childcare while still submitting assignments on time. Some are newly unemployed, fighting for income however they can, working night shifts and overtime, or several jobs at once. Too many of our students are dealing with several of the above simultaneously. We miss the classroom chatter, the smiles, the eye contact, the ability to check in with each person, and the way we used to be able say "I'm here for you" without having to say anything. While we fight the unmistakable unfairness of this situation as best we can, we take comfort in knowing that those two core principles of ecology are still true. Change is constant, and we will adapt to this new normal. No organism exists in isolation, even when sheltering in place forces us to hold class alone in our homes. 
Current task: We want to bring connections and interactions to the forefront, make the material flexible and accessible, and highlight the joy of fieldwork while knowing that experiencing the outdoors during a pandemic will look different for each student. Below is an example of how we're attempting to keep the joy of discovery and connection of ecology class alive while moving our instruction online.

\section{DIY Ecology lab: An Introduction to Biodiversity Sampling}

The face-to-face lab : In our face-to-face classes this lab is a bit of a field trip, group work exercise, and exploration trip all rolled into one. The lab objectives are to: introduce students to the types of data collection used in biodiversity studies; give the students an opportunity to apply the scientific method to biological questions by designing experiments and using the resulting data to form and communicate a conclusion; and allow students to describe patterns of biological diversity and discuss the biotic and physical processes that lead to these patterns. To meet these objectives we task students to answer the question "How does plant diversity change when moving from to edge of a particular habitat to the center?" The materials required are a $1 \mathrm{~m}^{2}$ PVC square, a reel measuring tape, and a digital camera (or a cell phone camera) for each group of four students. The data collection occurs in several habitats within a mile radius of campus, and collectively the students are taught how to perform a transect quadrat sample before breaking off into groups. Each group finds an area to sample, collects data, photographs the plant species encountered, then comes back to the lab to crunch the numbers and work toward a conclusion collectively. Back in the classroom student groups comingle, each helping another with the math involved or how to identify a certain plant species. We come together toward the end of the period to discuss the implications of the work and extrapolate what the results mean for fellow students and the larger community. By the time class is dismissed the students have been outside, had a hands-on experience, worked in groups and individually, identified plants to the genus or species level, calculated species density and percent frequency, recognized trends in their data, expressed a conclusion based on the data, and connected the class material to the greater community.

Challenges of moving this lab online: There are a few aspects of this lab that were challenging to transfer to an online format. First was the inability to physically show students how to use a quadrat or a transect for sampling. Usually we take our students into the field, huddle around our PVC quadrats, and do the first few samples as a group, but current social distancing guidelines makes this impossible. Instead we improvised with detailed written instructions and a YouTube video visually demonstrating the technique. The second hurdle was how to get the physical materials to the students so they could perform the data collection. Our campus only has a few quadrats, but if students work in groups our small set of materials is more than enough. However, with in-person group work forbidden, our small set of materials isn't adequate to supply every student with a quadrat each. Our solution to this problem was to make material procurement a do it yourself (DIY) task. We asked students to get creative and to make their own quadrats with material they could find at home or in the field. Some students used branches, bamboo sticks, or shovels, and some thought outside of the box. We saw quadrats made of pool noodles, jump ropes, leggings, floorboards, burdock roots, flow props, and large swords. The third, and most severe, challenge of taking this lab online was the loss of camaraderie. In normal times students cluster together over their samples, crawl on their hands and knees to identify plants, take photos of pretty flowers and group pictures to post on the Internet. Activities like these build interpersonal connections and trust. They allow students to relax and the expectations of the classroom float away once we're all outdoors. The social and emotional connections the students make are such a valuable part of the college experience. Sitting in the grass together allows bonds to be formed between students who may not have interacted in the classroom. Social distancing makes these moments feel impossible, but with the available technology we can create new ways for our students to interact. Our solution was to add a section to our class website discussion board called the "DIY quadrat show and tell" in which students submitted photos of their quadrats and can comment on the photos of others much like social media. This interaction, albeit through a computer screen, allows students to see that they are not alone. It's a visual reminder that they are part of a group, that they belong somewhere, and that 35 other people had to overcome the same challenges as they did this week. These interactions remind us that our class is a community and that even if we must be physically apart we're still in this together. 
Summary of the current lab : Before collecting data students read an overview explaining how ecological communities function, the importance of biodiversity, and the terms associated with quadrat sampling and transect sampling. A reminder to follow current social distance guidelines is bolded with the caveat that if going outside is not available to students this week an alternative assignment is available. We summarize the lab here, and provide the complete lab as Appendix I.

Research question : How does plant diversity change when moving from to edge of the habitat to the center?

\section{Summary of field directions :}

1. Create a DIY quadrat

2. Quadrat sampling in habitat of their choosing starting at the edge of the habitat and moving toward the interior

3. Collect data and identify plants to at least the genus level

4. Create a data table for each quadrat sample that includes the species name, species density, and percentage frequency

5. Conduct a minimum of 5 quadrat samples per student, record each sample with a photo

6. Answer the concluding questions

7. Insert the data tables and quadrat photos into the assignment write up

\section{Summary of discussion board:}

Students were given the following discussion board directions: "For this week's lab, you designed a homemade quadrant, and for your discussion post, I want you to show off your creation! Please post a photo and description caption of your DIY quadrant for all your lab buddies to appreciate. Then, reply to two of your classmate's posts who had your favorite creations. I know you can't wait to see how your classmates solved this problem!"

The full lab is available as Appendix I.

\section{Did it work?}

Meeting lab objectives : The students rose to the challenge of this online lab with enthusiasm and creativity (Figure 2). The data collected and results reached were of equal quality when compared with pervious face-to-face classes. It appears that the students were able to meet the lab objectives and that the crux of the activity was not lost by transitioning the material to an online format.

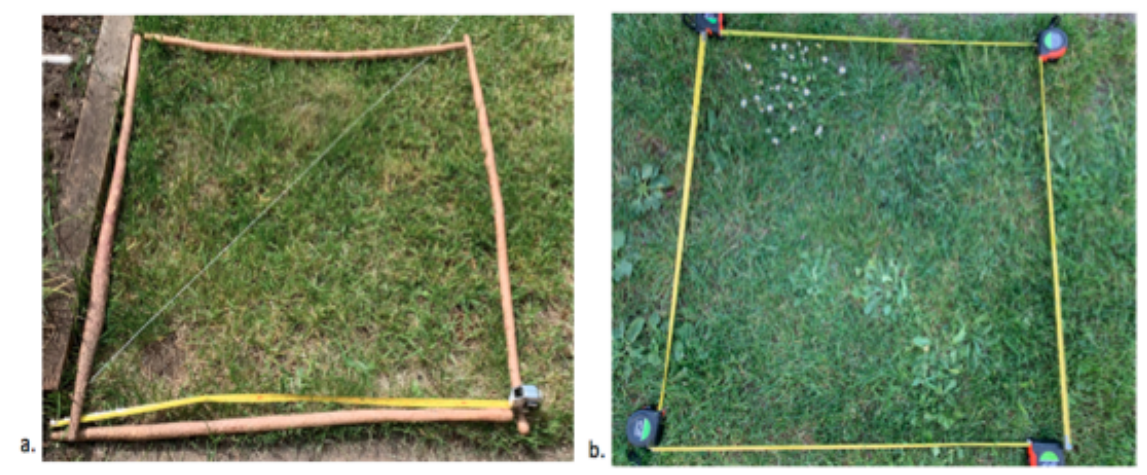




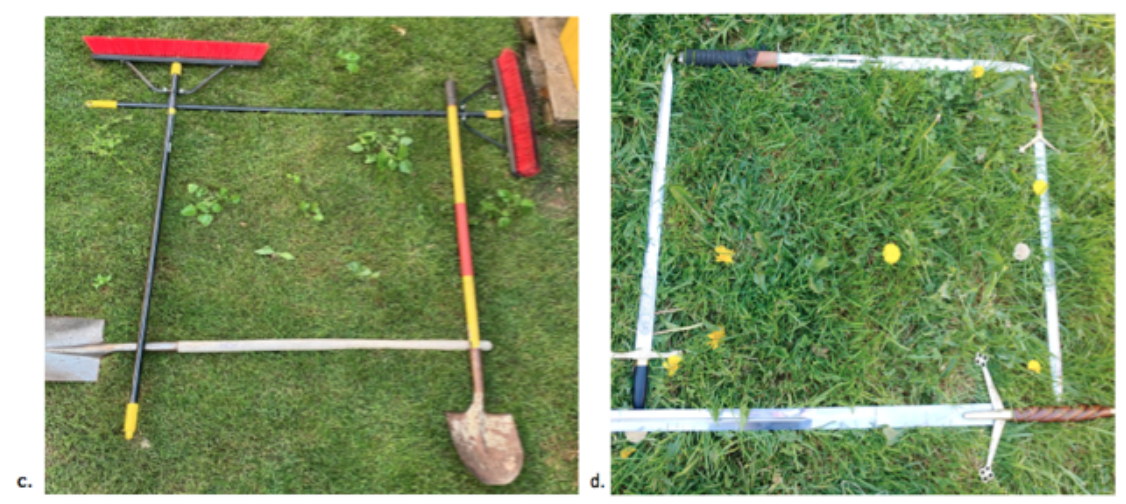

Figure 2. Examples of the student made quadrats composed of: a. burdock roots, b. measuring tapes, c. brooms and shovels, d. large swords.

Discussion board posts : Students in two joint sections of the remote ecology course $(\mathrm{n}=31)$ generated 103 discussion-post comments. Based on the tone and word choice it's clear that the discussion posted were used as a way to support and encourage each other, and to make social connections despite current social distancing.

Students used the comments to praise each other's experimental design: "Creative! Being able to use what you already have is great!" "I loved that the area you chose to do your lab at was different from the typical grassy areas." "I think it was very clever and resourceful of you to use pencils to stick into the ground to make sure the cords couldn't move!" "I think that your design looks wonderful." "Your design looks very creative and professional." Students also used the comments to provide each other with emotional and uplifting encouragement: "That was such a good idea!" "I am impressed, and I am also impressed at your creativity. Nice!" "WOW! This is so cool and creative!" "Wow you definitely went and created a cool square!" "I like how creative you got with using sticks, so rustic!"

Based on the responses, it seems that the students were happy overall with the online experience: "I wasn't even aware of quadrant sampling until this week. It was interesting to watch different YouTube videos and to see random people's perspectives on their DIY Quadrant." "I thought it was interesting since I looked closely for plants I would have just ignored." "It's amazing what we can think of if we are put in the position that we have to."

\section{Concluding remarks}

In the future there are a few things we would change to improve this lab. First, the guidelines for the discussion posts could be more detailed and constructive. The free-form responses were delightfully emotional and light-hearted, but the assignment could be improved by adding clearer expectations. Second, the conclusion of the lab could be reworked to allow more sharing of individual results. Possibly students could be asked to create a short PowerPoint or video explaining their answer to the research question and how they arrived at that conclusion. Third, the habitats the students sampled were not categorized. In the next version there will be a lab section about identifying the type of habitat and researching what plant species are common to those areas.

Our advice to other instructors is two-fold. One, be prepared for students in remote classes to be unsure of their work and need extra assurance that they are on the right track. Without being able to look over someone's shoulder in the classroom it's easy for students to feel lost and unguided. We've tried to mitigate this with frequent emails and class zoom meetings, but there still seems to be a high level of anxiety amongst the students that they will accidently do something wrong. The second piece of advice is to have an alternate assignment ready for anyone that is unable to leave home. Some of our students live in urban environments 
with little green space accessible to them under shelter-in-place requirements. For this lab the alternative assignments were to research different types of biodiversity sampling techniques and write a "how to" guide for five of them, or to write a literature review of two current peer-reviewed research articles based on biodiversity.

In summary, the theme of change as constant is ever present in our work as instructors. We see differences between class sections, between terms, and between years. We watch our students change over the course of the class, growing more confident and developing skills. We see ourselves change and grow as well, in our work and in our expectations for ourselves. When change is as startling and stark as is it has been lately it can be easy to feel alone, but we ecologists know a secret. We know that nothing in nature exists in isolation, especially not us, and especially not now. The COVID-19 pandemic has highlighted the ways that humans rely on each other. As we watch the world around us adjust to standing six feet apart, we know that human connection is immeasurable. We can still facilitate relationships through our instruction and foster community though digital interactions. And even though ecology class is different this term, it's still a faculty favorite.

\section{Appendix I}

\section{Ecology Lab: An Introduction to Biodiversity Sampling}

\section{Overview}

Ecological communities are built on the interactions between the organisms and the physical environment that surrounds them. The living organisms, or biotic factors, interact as predators, prey and competitors for resources. The physical environment, or abiotic factors, such as water, sunlight, climate, temperature, soil and oxygen are part of what determine how many living creatures can be supported in the ecosystem. Plants are important in ecological communities. Not only do plants represent a large source of primary production, they also determine the potential for wildlife to exist in an area. Disturbance of vegetation can have cascading effects through an ecosystem and changing the diversity and abundance of plants will affect the other living communities, such as animals, insects, fungi, and soil microbes (Schulz et al 2009). In particular, the more sunlight and water that is available in an area the greater the diversity of plants and animals can live in that area. For example, picture the difference between a desert and a tropical rainforest. The desert gets little water so not very many plants can grow there, which leads to few animals living there as well. In contrast, a tropical rainforest gets plenty of both sunlight and rain and hosts a wide variety of both plants and animals.

The question of how many species exists in an environment is central to understanding why it is important to promote and preserve species diversity. Promoting a singular species could leave an ecosystem at risk of failure when environmental conditions change (AMNH 2015). Biodiversity is a measure of the number and variety of different plant and animal species that live in an ecosystem. A high biodiversity can be correlated with a more stable ecosystem because there are a wider variety of resources for foraging, nesting, and seeking shelter. There is redundancy in resources as organisms can meet their needs in a variety of ways.

When studying an ecosystem, ecologists first try to survey what populations of organisms naturally live there, then measure how many of each organism lives there. This is referred to as the population density of that species. Ecologists measure population density by counting the number of each species in a sample area called a quadrat. If they count the population size in a number of quadrats chosen at random around the ecosystem, scientists can estimate how many of each species live in the whole ecosystem. The carrying capacity is how many individuals of a species that can survive in an area given the resources (food, water, and nesting sites) available (Folgia 2008). Quadrat sampling can either be random or systematic depending on the nature of your research question. In random quadrat sampling, the habitat is broken down into a grid-like system of squares and each square is assigned a number. Then a random number generator is used to 
select which square you will be observing. An example of systematic quadrat sampling is transect sampling, which simply means moving along a predetermined path, taking samples at predetermined regular intervals, such as from the edge of the habitat into the center. Sampling is done at regular distances to compare the biodiversity of the edge of the habitat with the interior.

In this lab you will be performing quadrat sampling to gauge the biodiversity of a habitat. You will get to choose where this habitat is but remember that you MUST follow social distancing protocols while completing this lab. If you can, complete this lab at your local park, in your yard/courtyard, or in a green area that's legally accessible. If you can't get outside, email me and we'll figure out an alternative.

Be sure to read this whole lab before you head out so you know exactly what is expected of you, and take photos of what you're doing as you go through this lab. You'll be asked to attach your photos to the conclusion before you submit this assignment.

\section{Research question}

How does plant diversity change when moving from to edge of the habitat to the center?

\section{Instructions}

First, watch this video showing you how to conduct a quadrat sample:

https://www.youtube.com/watch? $v=\operatorname{RhMOCxXcDrQ}$

Next, find something around your house that you can make a 1 meter x 1 meter square with. Here's what I found at my house, but you could also use rope, string, random branches, yardsticks, or whatever else you have lying around. Feel free to get creative!
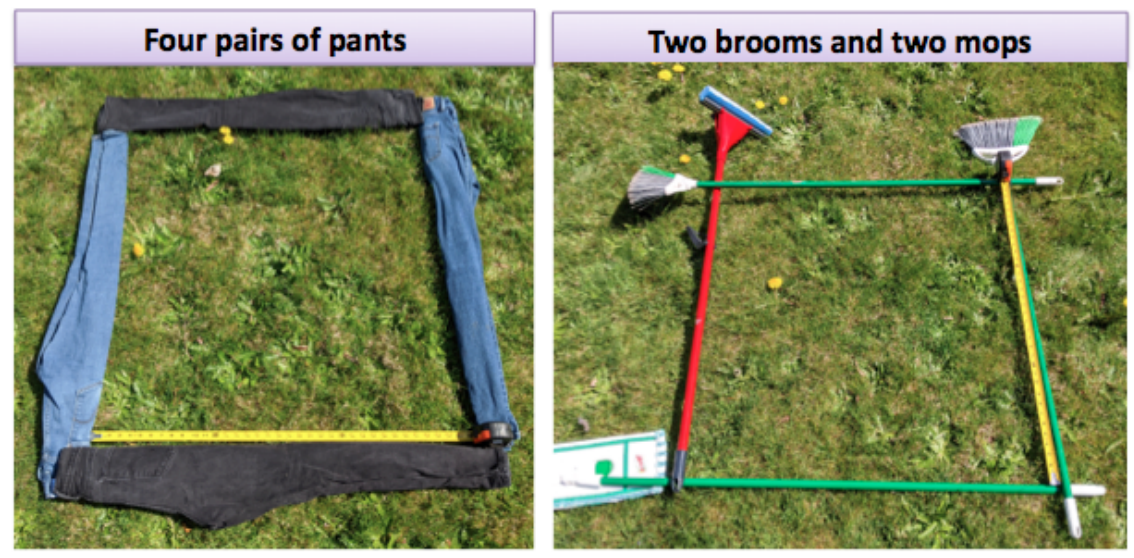

Ideally, you'll be able to find some way to make a meter squared box, but if you can't your quadrat can be smaller. As long as the size of your quadrat is consistent each time you use it, the experiment will work. Be sure to take a picture of your home-made quadrat. We'll be using it for the discussion this week.

We'll be using the transect method like the second technique shown in the video. This allows us to first determine the transect line that we would like to follow and use the quadrat to sample an equal amount of space at each predetermined point. That means that once you get to your habitat, you'll choose where on the edge to start and you'll aim toward the center of the area as you go.

Once you find a good spot, set down your quadrat to take your first data collection. To conduct the sampling within your quadrat, simply count the number of individuals of each species. You'll need to keep track of 
what species are present and how many of each there are, so you'll need to make a data table. Before you start, you'll need to decide how to deal with plants that are partly in and partly out of the quadrat. One possibility is to include plants that are more than half in and exclude ones less than half in. Another is to include all the border plants on the north and east sides and exclude all of those on the south and west sides.

\section{Answer the following questions before moving on:}

What did you use to make your quadrat? Don't forget to take a photo.

What rule did you adopt for plants that were partially inside the quadrat?

How did you decide where to conduct your first quadrat?

Before you collect your data, what do you think you'll see? Will there be a higher species diversity on the edge of the habitat or the center? Will the species change as you move, or will they be consistent thought the habitat?

As ecologists, we need to be keen observers of the habitat we are studying. Practice paying attention by listing four biotic factors and four abiotic factors in this ecological community.

Now we're ready to collect some data! Put down your $1 \mathrm{~m}^{2}$ quadrat at the first point intercept. Remember to orient yourself so that your data collected are applicable to your research question. Record the types plants and number of individuals of each species in the quadrat. Yes, you do need to accurately identify your plant species to at least to genus level, and don't forget to cite your sources. Common names of plants are not specific enough for this assignment. If you don't immediately recognize the plant, you can take a picture or a sample and identify it later. Your final report should include pictures (or diagrams) of each plant you find and each quadrat you set up.

After you have completely counted all individuals and species, move 3 meters along the transect line toward the interior of the research area and repeat the procedure. Do this four times so that you have data for five quadrat samples total .

Determine the density of each plant species within each quadrat and create a data table showing your results.

Density $=$ number of individuals of species

total individuals in quadrant

The percentage frequency is often used as a measure of abundance, especially in vegetation studies. Determine the percentage frequency for each species you observed and create a data table showing your results.

Percentage frequency $=$ total number of quadrats containing species $\mathrm{x} 100$

total number of quadrats

\section{Conclusion}

Answer the following questions then submit your assignment to our class Blackboard page. Don't forget to include the five questions you answered above as well!

1. What were your major results?

2. What is your answer to the research question?

3. Which plant species had the highest percentage frequency? Which had the lowest?

4. Which plant species had the highest density? Which had the lowest?

5. Is percentage frequency generally correlated with density? If no, why not? If yes, is the correlation perfect?

6. Why are changes in diversity important to determine?

7. What additional information would you like to get a more statistically accurate picture of this study population? 
8. How would the diversity of this habitat be impacted if we removed a quarter of an acre of vegetation from the interior, as opposed the edge? For example, if we were to build a house in this area, would it affect the habitat more to build it on the edge or in the interior?

9. Were any of the plant species you found invasive species? Which ones? If you didn't find an invasive species, look up a common one in your area for the next question.

10. How were the invasive species you found introduced to the area? What impact might they have on plant diversity and that of other taxa like arthropods, birds, and mammals? You are going to need to research this, so don't forget to cite your sources.

11. Insert your data tables. If another student redid this lab assignment in the same location in a week, do you think their data tables would look the same or different? If another student redid the assignment in three months from now, would the data tables look the same? Why or why not?

12. Insert your quadrat photos. Which quadrat sample had the most plant diversity based on number of species? Which quadrat had the highest density of plant based on number of individuals?

Data Accessibility Statement : The authors confirm that the data supporting the findings of this study are available within the article.

Competing Interests : None.

Author Contributions : Catherine Creech is the primary author and Walter Shriner is the supporting author.

Funding information : This paper is unfunded and the authors will be applying for a publication charge waiver and an open access fee waiver. We see our lack of funding as an important equity issue highlighting the differences in funding between community colleges and four-year universities. Almost half of all undergraduate students in the United States attend community college, but majority of publications about biology education research come from four-year universities (Schinske et al., 2017). These four-year universities tend to be large, predominantly white, $\mathrm{PhD}$ and master's degree granting institutions with more funding available for faculty publications. The voices of community college students and faculty should play a role in the conversation about how the COVID-19 pandemic is affecting the transition to online teaching.

Acknowledgments : We would like to thank the wonderful faculty, staff, and students of Mt. Hood Community College.

\section{References}

American Museum of Natural History (AMNH). 2015. How to Calculate Biodiversity Index. New York, New York [cited 11 July 2015]. Available from: http://www.amnh.org/explore/curriculumcollections/biodiversity-counts/plant-ecology/how-to-calculate-a-biodiversity-index

Folgia, Kim. 2008. Study of Population Density on a Suburban Lawn. Regents Biology [cited 11 July 2015]. Available from: http://www.explorebiology.com/regentsbiology/labs/

Kohn, C. 2011. Habitats \& Biodiversity Lab. W. Waterford, WI [cited 11 July 2015]. Agricultural Sciences. Available from: http://www2.waterforduhs.k12.wi.us/staffweb/ag/Website/Kohn-For-Teachers.html

Schinske, J. N., Balke, V. L., Bangera, M. G., Bonney, K. M., Brownell, S. E., Carter, R. S., .. Fletcher, L. (2017). Broadening participation in biology education research: Engaging community college students and faculty. Am Soc Cell Biol.

Schulz. B., Bechtold, W., Zarnoch, S. 2009. Sampling and Estimation Procedures for the Vegetation Diversity and Structure Indicator. United States Department of Agriculture, Forest Service, Pacific Northwest Research Station, General Technical Report PNW-GTR-781. [cited 11 July 2015] Available from: http://www.fs.fed.us/pnw/pubs/pnw_gtr781.pdf 